\title{
The value of percutaneous ultrasound in predicting conversion from laparoscopic to open cholecystectomy due to acute cholecystitis
}

\author{
Grzegorz Ćwik • Tomasz Skoczylas • \\ Justyna Wyroślak-Najs • Grzegorz Wallner
}

Received: 9 May 2012/ Accepted: 7 January 2013/Published online: 1 February 2013

(c) The Author(s) 2013. This article is published with open access at Springerlink.com

\begin{abstract}
Background Laparoscopic cholecystectomy has become the treatment of choice for gallstone disease. Advantages of the laparoscopic approach include lower morbidity and mortality rates, reduced length of hospital stay, and earlier return to work. In acute cholecystitis, severe inflammation makes laparoscopic dissection technically more demanding, with a higher risk of related complications that require conversion to open cholecystectomy.

Methods We reviewed the records of 5,596 patients who underwent cholecystectomy between 1993 and 2011 in a single institution. A laparoscopic approach was undertaken in 4,105 patients $(73.4 \%)$. The ultrasound signs of acute cholecystitis were found in 542 patients $(13.2 \%)$ who underwent laparoscopic cholecystectomy. We analyzed the ultrasound presentations of acute cholecystitis in patients who required conversion to open cholecystectomy and compared them with the ultrasound signs of acute cholecystitis in patients who had a completed laparoscopic cholecystectomy.

Results A conversion to open cholecystectomy in patients with acute cholecystitis was necessary in $24 \%(n=130)$ of the patients compared to $3.4 \%$ of the patients with uncomplicated gallstone disease. The most frequent ultrasound findings in patients requiring conversion were a pericholecystic exudate in $42 \%$, a difficult identification of
\end{abstract}

G. Ćwik · T. Skoczylas $(\bowtie) \cdot$ J. Wyroślak-Najs · G. Wallner Second Department of General \& Gastrointestinal Surgery \& Surgical Oncology of the Alimentary Tract, Medical University of Lublin, 20-081 Lublinul. Staszica 16, Poland

e-mail: tomskocz@yahoo.com

G. Ćwik

e-mail: grzegorzcwik@poczta.fm anatomical structures due to local severe inflammation in $34 \%$, and gallbladder wall thickening of $>5 \mathrm{~mm}$ in $31 \%$. Additionally, when the duration of symptoms exceeded 3 days, more than half of the patients required conversion to open cholecystectomy and the conversion rate was fivefold higher than for those with a shorter duration of acute cholecystitis.

Conclusions In patients with severe acute cholecystitis found on ultrasound, combined with gallbladder wall thickening to $>5 \mathrm{~mm}$, pericholecystic exudates or abscess adjacent to the gallbladder, difficulty identifying anatomical structures within Calot's triangle, specifically when the duration of symptoms exceeds 3 days, cholecystectomy should be done as an open approach because of the high risk of conversion.

Keywords Acute cholecystitis - Laparoscopic cholecystectomy · Open cholecystectomy · Conversion · Percutaneous ultrasound

Laparoscopic cholecystectomy ( $\mathrm{LCH}$ ) has become the method of choice in the treatment of symptomatic uncomplicated gallstone disease. The advantages of the laparoscopic approach include a shorter hospital stay and recovery time, reduced postoperative pain, and better cosmetic results [1-6]. The role of LCH in the treatment of complicated gallstone disease, and particularly acute cholecystitis, is still controversial and has been a subject of vigorous debate [2, 7-9]. Severe inflammation makes laparoscopic dissection technically more demanding, with a higher wall perforation rate and spillage of the infected bile into the peritoneal cavity [2]. Infiltration of inflammation may disturb the anatomy of Calot's triangle resulting in an increased risk of bile duct injury. Severe inflammation is also responsible for serious 
complications occurring in the postoperative course [10-12]. For several years after $\mathrm{LCH}$ had been introduced, some authors have suggested that acute cholecystitis is a contraindication for the laparoscopic approach $[2,6,8]$. However, with experience and increased skills in laparoscopic techniques, acute cholecystitis, excluding its gangrenous form, ceased to preclude $\mathrm{LCH}[3,9,13,14]$.

Many publications pointed out that age over 60-65, previous upper abdominal surgery, clinical and ultrasound signs of severe acute cholecystitis at admission, and white blood count $(\mathrm{WBC})>10.0 \mathrm{k} / \mu \mathrm{L}$ were significantly associated with conversion to open cholecystectomy (OCH) $[1,2$, $5,15]$. Recently, an increasing number of reports have indicated that LCH is a safe method of treatment for acute cholecystitis, especially due to the improvement in surgical technique and instrumentation. The established limitations for use of LCH include the operating surgeon's experience and the degree of inflammation, especially in seriously complicated cases $[1,2,7,13,16]$. Patients with acute cholecystitis are usually informed of the potential for conversion to open cholecystectomy when it is difficult to identify the main anatomic structures $[5,17,18]$. A conversion may prevent a severe complication such as injury to the biliary tree.

The aim of the study was to review comprehensively the indications and contraindications of the use of LCH in acute cholecystitis patients based on ultrasound presentation. Additional objectives of our analysis included identifying the most common causes of conversion from laparoscopic to open cholecystectomy and to define to what extent and in what cases it may be predicted via percutaneous ultrasound.

\section{Materials and methods}

We retrospectively reviewed the records of 5,596 patients who underwent cholecystectomy for gallstone disease between 1993 and 2011 in a single tertiary-care institution (Second Department of General \& Gastrointestinal Surgery \& Surgical Oncology of the Alimentary Tract, Medical University of Lublin, Poland). The investigator (GĆ) who performed the preoperative ultrasound assessment was blinded to the intraoperative decision about conversion. A laparoscopic approach was undertaken in 4,105 patients (73.4\%). A decision about whether to initially use an open or a laparoscopic approach was made based on clinical presentation, ultrasound findings assessed in the department directly before the operation, and blood tests such as WBC and/or C-reactive protein.

On percutaneous ultrasound, special attention was paid to the thickness of the gallbladder wall, the echo pattern of the gallbladder lumen, the presence of fluid within the gallbladder wall or its closest surroundings, and fluid collections in the peritoneal cavity. The anatomic area covering the gallbladder neck, common bile duct (CBD), and neighboring vascular structures were subsequently identified. The intensity of infiltration of inflammation was assessed by the degree of obscuration of anatomic details within Calot's triangle. Then, the width and contents of the $\mathrm{CBD}$ and the size and echogenic pattern of the pancreas were assessed.

Percutaneous ultrasound revealed signs of acute cholecystitis, such as wall thickening of $>4 \mathrm{~mm}$, stagnant or purulent gallbladder contents, and intramural or pericholecystic exudate, in 829 patients (14.8\% of 5,596 patients). LCH was undertaken in 542 patients $(65.4 \%$ of 829 patients) with acute cholecystitis. The remaining 287 patients (34.6\% of 829 patients) were primarily referred for $\mathrm{OCH}$. The most frequent reasons for preclusion of $\mathrm{LCH}$ were signs of peritonitis, a suspicion of gangrenous cholecystitis or gallbladder wall perforation with an adjacent abscess, a rapid increase of bilirubin, a severe inflammatory infiltrate that hindered the interpretation of anatomic details on ultrasound, an emergency indication, or the patient's refusal to undergo the laparoscopic approach.

An elevated bilirubin level was found on preliminary assessment in 187 patients (34.5\% of 542 patients) with acute cholecystitis who underwent LCH. In most cases it was caused by the inflammatory reaction in the region of the gallbladder neck and Calot's triangle and was reduced after administration of antibiotics. In 61 patients $(11.3 \%$ of 542 patients) with acute cholecystitis who underwent $\mathrm{LCH}$, ductal stones or dilatation of the CBD $>10 \mathrm{~mm}$ was identified on ultrasound. In all these patients endoscopic sphincterotomy (ES) was performed before surgery, which was effective in 50 patients who were subsequently referred for LCH to be done the next day or 2 weeks after ES. The remaining 11 patients with ductal stones or dilated CBD qualified for $\mathrm{OCH}$ with bile duct exploration.

The initial classification of gallbladder inflammation as acute cholecystitis correlated with the histopathological evaluation of the removed specimen.

Additional ultrasound assessment was carried out if intense abdominal pain and fever persisted after the surgery and if laboratory tests revealed abnormalities, which usually occurred 2 or 3 days after the operation.

Follow-up was scheduled 30 days after surgery and 412 patients $(76 \%)$ showed up for the examination. Percutaneous ultrasound was used to evaluate the postcholecystectomy site, the width and shape of the CBD, and the echogenic pattern and size of the pancreas.

Statistical analysis was conducted using the STATISTICA software (StatSoft, Inc., Tulsa, OK). The differences between groups were compared using the $\chi^{2}$ test. A $P$ value lower than 0.05 was regarded as significant. 


\section{Results}

We identified 542 patients with symptoms and signs of acute cholecystitis who were referred for LCH. All suffered from typical pain, intermittent to constant fever, increased WBC $>10.0 \mathrm{k} / \mu \mathrm{L}$, and at least one of the ultrasound features of acute cholecystitis mentioned above. Conversion from laparoscopic to open cholecystectomy was necessary in 130 patients $(24 \%)$. LCH was performed by a team led or supervised by an experienced laparoscopic surgeon ( $>100 \mathrm{LCH}$ ) who made the decision to convert. The conversion rate in patients who were undergoing $\mathrm{LCH}$ due to uncomplicated gallstone disease was $3.8 \%$. The reasons for conversion are listed in Table 1. The most common causes of conversion found in the initial phase of laparoscopy were the lack of confidence in identification of the cystic duct $(36.2 \%)$, massive inflammatory or postoperative adhesions $(25.3 \%)$, and flaccid gangrenous gallbladder $(22.3 \%)$. Common bile duct injuries occurred in three patients who underwent $\mathrm{LCH}$ for acute cholecystitis $(0.5 \%)$. The injuries were detected in all of them intraoperatively and required conversion to open access and were repaired with Roux-en-Y hepaticojejunostomy.

Comparison of the ultrasound presentation of the gallbladder and its surroundings for patients who required conversion to the open approach to the ultrasound findings for patients who underwent a completed $\mathrm{LCH}$ are given in Table 2. The most frequent findings on preoperative ultrasound in patients converted to $\mathrm{OCH}$ included obscured anatomy at the gallbladder neck, cystic duct and CBD linked to a local inflammatory infiltrate in 52 patients (40.0\%), pericholecystic exudate in 44 patients $(33.8 \%)$, and thickening of the gallbladder wall of more than $5 \mathrm{~mm}$ in 41 patients $(31.5 \%)$. Other ultrasound abnormalities occurred less frequently. In the patients who had a completed LCH, the ultrasound signs of acute cholecystitis were less intense. The most frequent findings included thickening of the gallbladder wall to $3-5 \mathrm{~mm}$ in 258 patients $(62.6 \%)$, a tense and enlarged gallbladder in 112

Table 1 The distribution of reasons for conversion from laparoscopic to open cholecystectomy in patients operated on for acute cholecystitis

\begin{tabular}{lrr}
\hline Cause of conversion & $n$ & $\%$ \\
\hline Impossible identification of the cystic duct & 47 & 36.2 \\
Massive inflammatory or postoperative adhesions & 33 & 25.3 \\
Flaccid gangrenous gallbladder & 29 & 22.3 \\
Intensive bleeding & 11 & 8.5 \\
Necessity to explore the CBD & 7 & 5.4 \\
CBD injury & 3 & 2.3 \\
Total & 130 & \\
\hline
\end{tabular}

patients $(27.2 \%)$, pericholecystic exudate in 76 patients $(18.4 \%)$, and intramural exudate in 67 patients $(16.3 \%)$. Statistical analysis revealed significant differences between converted and completed LCH patients. The thickening of the gallbladder wall to more than $5 \mathrm{~mm}$ (31.5 vs. $8.8 \%$, $P<0.000001)$, pericholecystic exudate (33.8 vs. $18.4 \%$, $P=0.002)$, abscess adjacent to the gallbladder (17.7 vs. $6.6 \%, P=0.0001)$, intensive gallbladder wall deformation (21.5 vs. $9.2 \%, P=0.0002)$, and difficulty identifying anatomical structures (40.0 vs. $23.3 \%, P=0.003$ ) more frequently predicted conversion to $\mathrm{OCH}$. On the other hand, the thickening of the gallbladder wall to $3-5 \mathrm{~mm}$ more frequently predicted successful completion of $\mathrm{LCH}$ (62.6 vs. $13.8 \%, P<0.000001)$. The analysis of the ultrasound findings for patients with acute cholecystitis who were undergoing $\mathrm{LCH}$ and required conversion did not reveal significant differences between those who were operated on in the early period (1993-2001) and those in the late period (2002-2011) (Table 2).

In patients who required conversion, ultrasound findings of acute cholecystitis usually were combined with two or three other components such as concomitant thickening of the gallbladder wall to more than $5 \mathrm{~mm}$, obscured anatomy of Calot's triangle, and pericholecystic exudate or abscess. The number of concomitant ultrasound findings had considerable influence on the risk of conversion, especially in patients with three simultaneous findings (Table 3). A combination of at least two of these findings with acute cholecystitis resulted in a conversion rate $>70 \%$. Under these circumstances, slow dissection and difficulty in identifying anatomical structures frequently and remarkably limited even the experienced laparoscopist.

Additionally, the conversion rate significantly correlated with duration of symptoms of acute cholecystitis (Fig. 1). The mean time from the onset of symptoms to surgery for patients who underwent $\mathrm{LCH}$ and required conversion was 1.26 days longer than for patients who underwent completed LCH (Table 4). When the duration of symptoms was 4 or more days, more than half of the patients required conversion to open cholecystectomy and the conversion rate was fivefold higher than in patients with a shorter duration of symptoms (Fig. 1; Table 4).

On the follow-up ultrasound performed 30 days after $\mathrm{LCH}$, a CBD dilated to $>10 \mathrm{~mm}$ was found in 25 of 412 patients $(6.0 \%)$. Only $9(2.2 \%)$ symptomatic patients with confirmed ductal stones required ES and stone extraction.

\section{Discussion}

In the last two decades, LCH has become the standard treatment of symptomatic gallstone disease [2, 4, 5, 19]. $\mathrm{LCH}$ is a widely recommended method for both complicated 
Table 2 Ultrasound presentation of the gallbladder in patients with acute cholecystitis who underwent laparoscopic cholecystectomy and required conversion to the open approach

\begin{tabular}{|c|c|c|c|c|c|c|c|c|c|}
\hline \multirow[t]{2}{*}{ Ultrasound finding } & \multicolumn{2}{|c|}{ CONV } & \multicolumn{2}{|c|}{ LCH } & \multirow[b]{2}{*}{$P$} & \multicolumn{2}{|c|}{ CONV I } & \multicolumn{2}{|c|}{ CONV II } \\
\hline & $n$ & $\%$ & $n$ & $\%$ & & $n$ & $\%$ & $n$ & $\%$ \\
\hline GB wall thickening $3-5 \mathrm{~mm}$ & 18 & 13.8 & 258 & 62.6 & $<0.000001$ & 10 & 14.5 & 8 & 13.1 \\
\hline GB wall thickening $>5 \mathrm{~mm}$ & 41 & 31.5 & 36 & 8.8 & $<0.000001$ & 22 & 31.9 & 19 & 31.1 \\
\hline Intramural exudate & 24 & 18.5 & 67 & 16.3 & 0.56 & 16 & 23.2 & 8 & 13.1 \\
\hline Pericholecystic exudate & 44 & 33.8 & 76 & 18.4 & 0.002 & 25 & 36.2 & 19 & 31.1 \\
\hline Suspected GB wall gangrene & 21 & 16.1 & 42 & 10.2 & 0.06 & 10 & 14.5 & 11 & 18.0 \\
\hline Pericholecystic abscess & 23 & 17.7 & 27 & 6.6 & 0.0001 & 13 & 18.8 & 10 & 16.4 \\
\hline Intensive GB wall deformation & 28 & 21.5 & 38 & 9.2 & 0.0002 & 15 & 21.7 & 13 & 21.3 \\
\hline Difficult identification of anatomical structures & 52 & 40.0 & 96 & 23.3 & 0.003 & 26 & 37.7 & 26 & 42.6 \\
\hline Tense, enlarged GB & 31 & 23.8 & 112 & 27.2 & 0.45 & 15 & 21.7 & 16 & 26.2 \\
\hline Total number of patients & 130 & & 412 & & & 69 & & 61 & \\
\hline
\end{tabular}

The differences between groups were calculated using $\chi^{2}$ test; $P$ is the level of significance

LCH patients who had a completed laparoscopic cholecystectomy, CONV patients who started with a laparoscopic cholecystectomy and then required conversion to open cholecystectomy, CONV I patients who started with laparoscopic cholecystectomy and then required conversion to open cholecystectomy between 1993 and 2002, CONV II patients who started with laparoscopic cholecystectomy and then required conversion to open cholecystectomy between 2003 and 2011, GB gallbladder

Table 3 Number of ultrasound findings identified simultaneously with acute cholecystitis in patients who underwent conversion from laparoscopic to open cholecystectomy

\begin{tabular}{lrc}
\hline No. of ultrasound findings & $n$ & $\%$ \\
\hline 1 & 35 & 26.9 \\
2 & 38 & 29.2 \\
3 & 57 & 43.9 \\
Total No. of patients & 130 & \\
\hline
\end{tabular}

and uncomplicated disease $[3,8,13,16]$. Conversion to $\mathrm{OCH}$ is occasionally necessary to avoid injury to the CBD and to clarify obscured anatomy. The conversion rate in uncomplicated gallstone disease is low, ranging between 1 and $6 \%$; in our series it reached $3.8 \%[5,11,13-15]$. Slim women under 65 , with a short duration of the disease and an uncomplicated presentation on ultrasound, are at the lowest risk of conversion $[5,11]$.

In patients with acute cholecystitis, the conversion rate is higher, i.e., $22 \%[2,7,11,20,21]$, and in some reports it is as high as $35 \%[4,9,13,18,22]$. In our series the conversion rate in acute cholecystitis patients was $24 \%$. Factors that increase the risk of conversion include the duration of acute symptoms, great damage to the gallbladder wall, inflammatory infiltration of the components of Calot's triangle, adhesions in the upper part of the abdominal cavity, and intraoperative complications. It has been established that 72-96 $\mathrm{h}$ from admission to the hospital is the optimal time to perform cholecystectomy in acute cholecystitis, since thereafter the risk of complications increases significantly $[4,6,14]$. If an elevated WBC does not decrease and the clinical presentation is not alleviated within 4 days while on antibiotic therapy, the patient should be referred for OCH [17]. Few studies have focused on the proper timing of surgical intervention for acute cholecystitis, but, in general, 4 days of complaints has been proposed as the cutoff point after which the conversion rate rises significantly $[4,6,14,23,24]$. Our data showed that if the symptoms lasted 4 or more days, more than half of the patients required conversion to open cholecystectomy and the conversion rate was fivefold higher than in patients with a shorter duration of symptoms (Table 4; Fig. 1).

Previous upper abdominal surgery increases the risk for conversion to $\mathrm{OCH}$, up to as much as $25 \%$ [5, 19, 25]. Peritoneal adhesions make access to the gallbladder difficult. Dense adhesions surrounding the gallbladder and adhesions between the CBD, cystic duct, and cystic artery (Calot's triangle) clearly obscure the field of view during surgery. These conditions may significantly prolong laparoscopic dissection and may result in bleeding or gallbladder rupture $[2,26]$. In patients suspected of having dense adhesions, the open technique should be the initial treatment of choice $[5,6,16,25]$.

The extent of the weakening of the gallbladder wall is another cause of an increased risk of conversion [2, 13, 26, 27]. A gangrenous gallbladder may result in a disruption of wall continuity, flaccidity, and tendency to laceration during retraction and removal. Inflammation of the gallbladder greatly increases the risk of wall damage up to $34 \%$, which in turn may result in a higher rate of conversion, reaching $23 \%$ [2]. Some authors regard a 
Fig. 1 Time from the onset of symptoms of acute cholecystitis to surgery in patients who underwent laparoscopic cholecystectomy and required conversion. $\mathrm{LCH}$ patients who had a completed laparoscopic cholecystectomy, $\mathrm{CONV}$ patients who started with laparoscopic cholecystectomy and then required conversion to open cholecystectomy, $\mathrm{P}$ is the level of significance, and the differences between groups were calculated using $\chi^{2}$ test

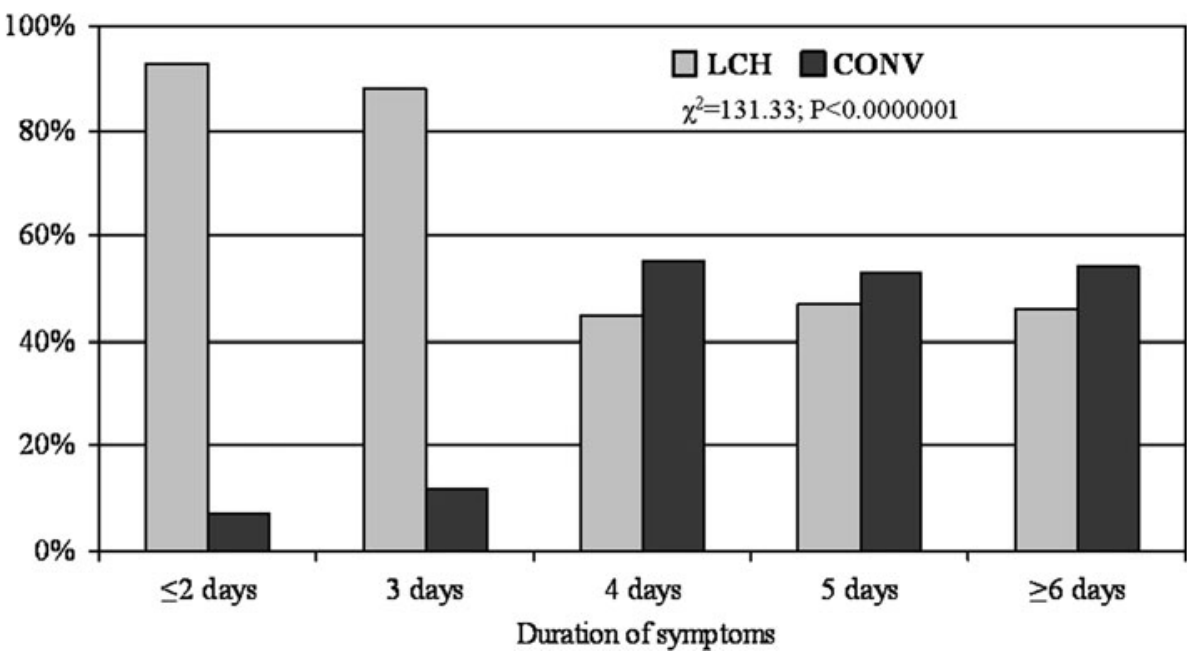

Table 4 Time from the onset of symptoms of acute cholecystitis to surgery in patients who underwent laparoscopic cholecystectomy and required conversion

\begin{tabular}{|c|c|c|c|c|c|}
\hline \multirow[t]{2}{*}{ Duration of symptoms } & \multicolumn{2}{|c|}{$\mathrm{LCH}$} & \multicolumn{2}{|c|}{ CONV } & \multirow[b]{2}{*}{$P$} \\
\hline & $n$ & $\%$ & $n$ & $\%$ & \\
\hline$\leq 2$ days & 168 & 92.8 & 13 & 7.2 & $<0.0000001$ \\
\hline 3 days & 164 & 88.2 & 22 & 11.8 & \\
\hline 4 days & 33 & 44.6 & 41 & 55.4 & \\
\hline 5 days & 30 & 46.9 & 34 & 53.1 & \\
\hline$\geq 6$ days & 17 & 45.9 & 20 & 54.1 & \\
\hline Total no. of patients & 412 & & 130 & & \\
\hline $\begin{array}{l}\text { Mean duration of symptoms } \\
\text { (days) }\end{array}$ & 2.94 & & 4.20 & & \\
\hline
\end{tabular}

$P$ is the level of significance, the differences between groups were calculated using $\chi^{2}$ test $\left(\chi^{2}=131.33\right)$

$L C H$ patients who had a completed laparoscopic cholecystectomy, $C O N V$ patients who started with laparoscopic cholecystectomy and then required conversion to open cholecystectomy

gangrenous gallbladder as direct indication for choosing the open approach due to a high rate of conversion and postoperative complications [13, 14]. This is exemplified by the increased conversion rate associated with the different degrees of inflammation: $40 \%$ in gangrenous cholecystitis [4], $71 \%$ in phlegmonous cholecystitis [17], and $12 \%$ in empyema of the gallbladder [15].

Thickening of the gallbladder wall to $>5 \mathrm{~mm}$ that is related to ongoing acute inflammation and inflammatory infiltration of the neck and Calot's triangle are other important causes of conversion [3-5, 10, 23]. Severe inflammation in this crucial anatomic area make some surgeons perform such unconventional procedures as laparoscopic subtotal cholecystectomy [10] or percutaneous cholecystostomy [12] because of difficulty in identifying the local anatomy and the risk of injury to important structures such as the CBD and the hepatic artery. For surgeons with low experience, if a bile duct injury does occur, it is usually during the first 25 cholecystectomies [9]. It occurs less frequently for experienced laparoscopists who are able to evaluate the risk properly and make the decision early to convert $[2,5,23]$. The level of experience of the surgeon has a considerable impact on conversion rate, with longer operation times and more intraoperative complications for junior residents [19, 28]. Increased experience in preoperative and intraoperative assessment results in a change of distribution between $\mathrm{LCH}$ and $\mathrm{OCH}$ $[2,4,18]$ and the majority of conversions occur in the first months and years of the learning curve $[4,9,16,18,29]$. That was the case in our department, where LCH was preferred in only $62-73 \%$ of symptomatic uncomplicated gallstone disease cases during the first 4 years compared with $95 \%$ of the cases in the last 10 years. Moreover, $\mathrm{LCH}$ is preferred more frequently for patients with acute cholecystitis, where the only contraindication is severe clinical signs accompanied by multiple simultaneous findings of severe inflammation on ultrasound.

One of the most severe complications of cholecystectomy is injury to the $\mathrm{CBD}$. For $\mathrm{OCH}$, the prevalence of bile duct injury has been estimated to be $0.1-0.2 \%$, but for $\mathrm{LCH}$, the rate has been reported as high as $0.5 \%[5,9,30$, 31]. The most common causes of CBD injury are the failure to recognize the anatomy of Calot's triangle, inadequate experience of the surgeon, and local anatomical risk factors. In our series of patients with acute cholecystitis, we identified three cases of serious CBD injury during $\mathrm{LCH}$ $(0.55 \%)$. All were detected intraoperatively and required conversion to open access and were repaired with Roux-en$\mathrm{Y}$ hepaticojejunostomy.

Conversion to $\mathrm{OCH}$ has been associated with a longer operative time, the use of more anesthetics, increased overall morbidity, a higher rate of infective complications, 
longer recovery time, longer hospital stay, higher cost, and greater patient dissatisfaction $[5,19,29,32-34]$. Thus, the ability to predict preoperatively the technical difficulties that may occur during surgery in order to choose between the laparoscopic or the open approach is desirable.

Concomitant choledocholithiasis, usually found in $10-12 \%$ of the cases, is not a direct contraindication for $\mathrm{LCH}$ as long as ductal calculi are removed endoscopically before or sometimes after the operation, or during $\mathrm{LCH}$ by transcystic or direct laparoscopic CBD exploration [9, 26, $27,29,35]$. The principal issue is to establish indications for ES. The primary diagnostic imaging method used to check for indications to use ES and CBD exploration is percutaneous ultrasound, although its limitations in the evaluation of the bile ducts narrow its sensitivity to 68-94\% [32]. Moreover, serum testing for bilirubin level, alkaline phosphatase, liver transaminases, and lipase should be assessed initially and monitored during the course of the disease [14, 19, 27, 32, 35]. In most cases, a raised bilirubin level in acute cholecystitis results from inflammatory infiltration of Calot's triangle and decreases after the implementation of antibiotic therapy [4, 17, 33]. An elevated bilirubin level may also be associated with Mirizzi syndrome, which in turn may increase the probability of conversion [19, 36].

A thickening and deformation of the gallbladder wall and signs mimicking gross inflammation in patients over 60 may result from the gallbladder cancer, which occurs in $3-10 \%$ of gallbladder disease cases [20, 22]. LCH is not recommended in cancer patients as it generally does not provide a potential for cure and may contribute to peritoneal dissemination and port site metastasis [20]. If cancer is found during $\mathrm{LCH}$, conversion to open and more radical surgery, including removal of the port sites, should be performed in all resectable cases [22].

Acute cholecystitis does not preclude LCH. However, there are certain constraints in the application of this technique, particularly in patients with a gross inflammatory reaction $[10,13,17]$. Is it possible to establish the contraindications for LCH? We can try to answer this difficult question by identifying the causes of conversion. The compiled statistical analysis failed to define predictors unequivocally. A considerable thickening of the gallbladder wall, impeded orientation in cirrhotic changes, gallstone disease in men over 65 , and palpable gallbladder mass on physical examination were found to be the most frequent causes of conversion [1, 15, 21, 24, 34]. Additional significant reasons for conversion to $\mathrm{OCH}$ include intraperitoneal adhesions, obscured anatomy, obesity, old age, male gender, persistent fever, and ultrasound findings of acute cholecystitis $[5,11,15,17-19,31,33]$. An elevated level of alkaline phosphatase $>200 \mathrm{IU}$, amylase $\geq 150 \mathrm{U} / \mathrm{L}$, lipase $\geq 128 \mathrm{U} / \mathrm{L}$, WBC $>14.0 \mathrm{k} / \mu \mathrm{L}$, APACHE II score $>10$ points, and raised LDH level significantly also increase the risk of conversion [11, 19, 33]. In multivariate analysis, a body mass index $(\mathrm{BMI})>25-30 \mathrm{~kg} / \mathrm{m}^{2}$ was identified as an important predictor of conversion [1, 15, 19]. Additionally, a delay of surgery of more than $72 \mathrm{~h}$ from the time of admission with concomitant acute symptoms of inflammation was frequently associated with conversion $[19,23]$. All of the above-mentioned scoring systems and predictive factors have demonstrated inconsistent value, and none has been widely incorporated into surgical practice [19].

Preoperative diagnostic procedures should support the decision for the appropriate surgical approach. Percutaneous ultrasound is a simple diagnostic technique that provides essential information on inflammatory complications that could affect the outcome of surgery. The most commonly discussed ultrasound findings include thickening of the gallbladder wall to $\geq 4 \mathrm{~mm}$ (Fig. 2) [5, 6, 18, 21, 29], pericholecystic exudate (Fig. 3) [7, 15, 19, 37, 38], edematous gallbladder wall (intramural exudate) (Fig. 4) [1, 15], Murphy's sign on ultrasound [5, 15, 26, 36, 37], a distended gallbladder obstructed by stones [1, 6, 18, 29, 36], and pericholecystic abscess (Fig. 5) [1]. Ultrasound signs of inflammation result in a 7-8.5-fold higher rate of conversion to $\mathrm{OCH}[3,15,19,33]$. Other ultrasound findings that can predict technical difficulties during $\mathrm{LCH}$ include excessive gallbladder volume, impacted stones in the gallbladder neck, ductal stones, size of the largest gallstone, color or power Doppler signs within the gallbladder wall or in the adjacent liver, and pattern of gallbladder wall thickening $[6,18,19,25,29,34,37]$.

Our large series identified ultrasound presentations of acute cholecystitis, such as gallbladder wall thickening to more than $5 \mathrm{~mm}$, pericholecystic exudate, abscess adjacent to the gallbladder, intense gallbladder wall deformation, and difficulty in identifying anatomical structures, as significant predictive factors of conversion to $\mathrm{OCH}$. On the other hand, gallbladder wall thickening to $3-5 \mathrm{~mm}$ more frequently predicted successful completion of $\mathrm{LCH}$. Moreover, ultrasound presentation of a combination of at least two of the following signs: thickening of the gallbladder wall to more than $5 \mathrm{~mm}$, blurred anatomy of Calot's triangle, and pericholecystic exudate or abscess, resulted in a conversion rate exceeding $70 \%$. Therefore, ultrasound assessment assists the surgeon in preoperative or intraoperative decision making. In patients with severe inflammation found on ultrasound combined with gallbladder wall thickening to more than $5 \mathrm{~mm}$, pericholecystic exudate or abscess adjacent to the gallbladder, and difficulty in identifying anatomical structures within $\mathrm{Ca}$ lot's triangle, specifically when the symptoms have lasted more than 3 days, open cholecystectomy should be used because the risk of conversion from $\mathrm{LCH}$ is high, even for 


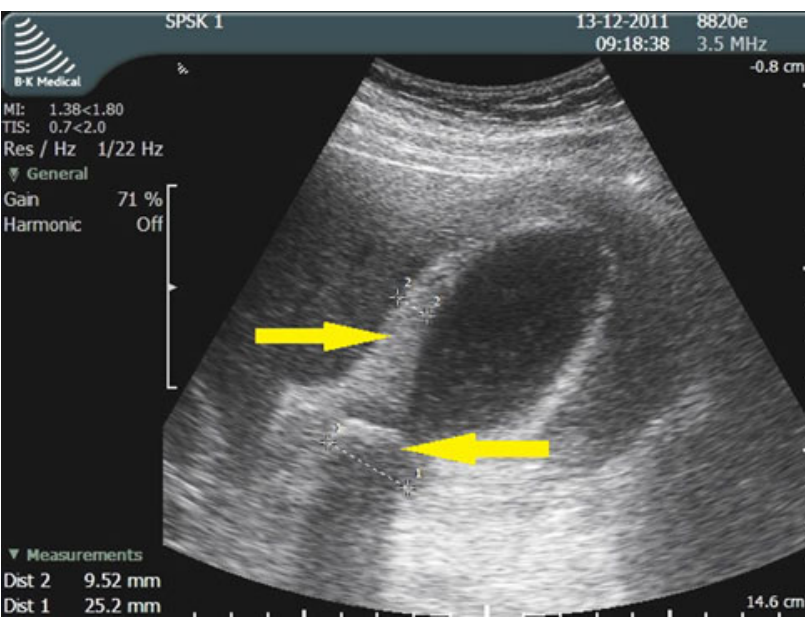

Fig. 2 Ultrasound findings in acute cholecystitis that could affect the outcome of surgery: severe thickening of the gallbladder wall (8-9 mm), a large stone obstructing the gallbladder neck, and deformation of Calot's triangle

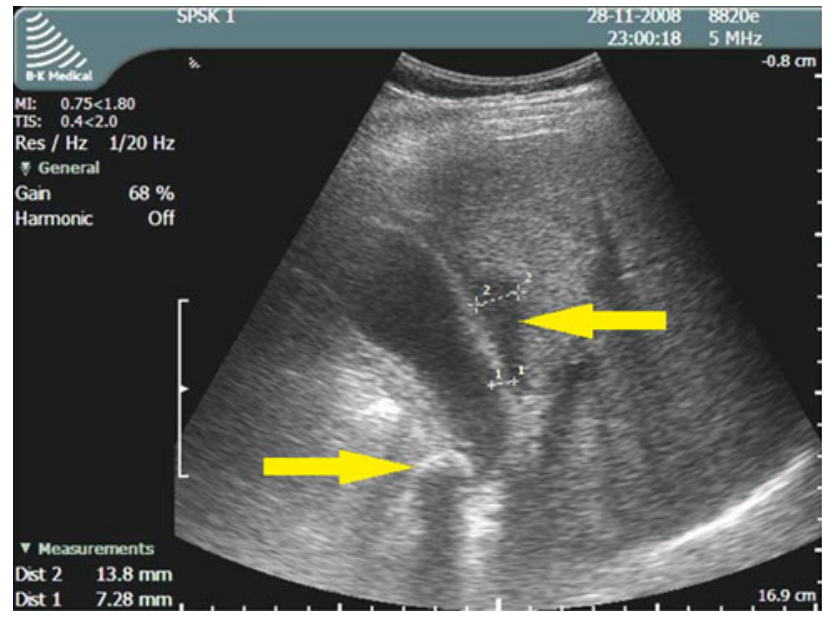

Fig. 3 Ultrasound findings in acute cholecystitis that could affect the outcome of surgery: the gallbladder obstructed by a large stone, inflammation of the gallbladder wall, and pericholecystic exudate separating the liver bed

the experienced laparoscopic surgeon. This approach may save operating time and reduce overall cost by not having to convert from $\mathrm{LCH}[6,37,38]$.

Disclosures Drs. Grzegorz Ćwik, Tomasz Skoczylas, Justyna Wyroślak-Najs, and Professor Grzegorz Wallner have no conflicts of interest or financial ties to disclose.

Open Access This article is distributed under the terms of the Creative Commons Attribution License which permits any use, distribution, and reproduction in any medium, provided the original author(s) and the source are credited.

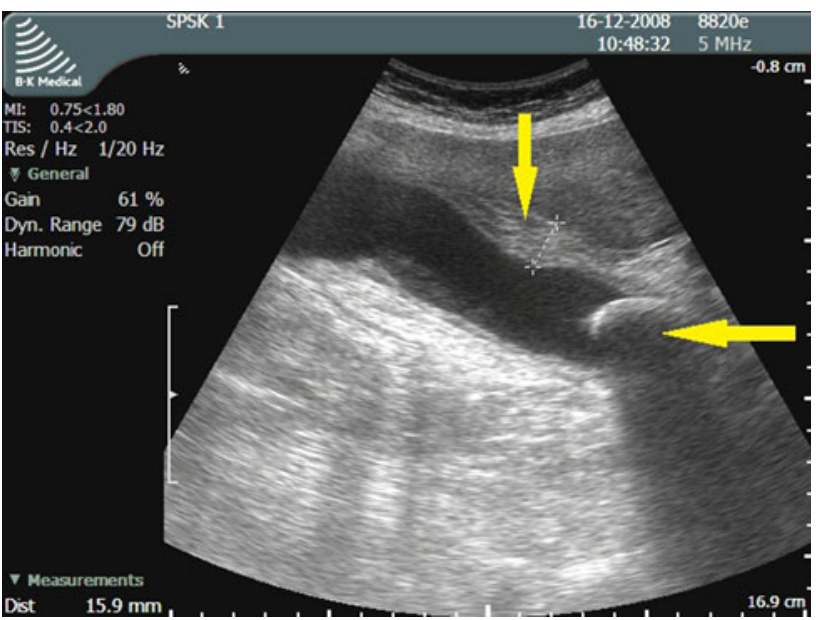

Fig. 4 Ultrasound findings in acute cholecystitis that could affect the outcome of surgery: the gallbladder with a severely thickened wall, obstructed by a stone, with pericholecystic exudate; large deformation of Calot's triangle makes identification of anatomical structures impossible

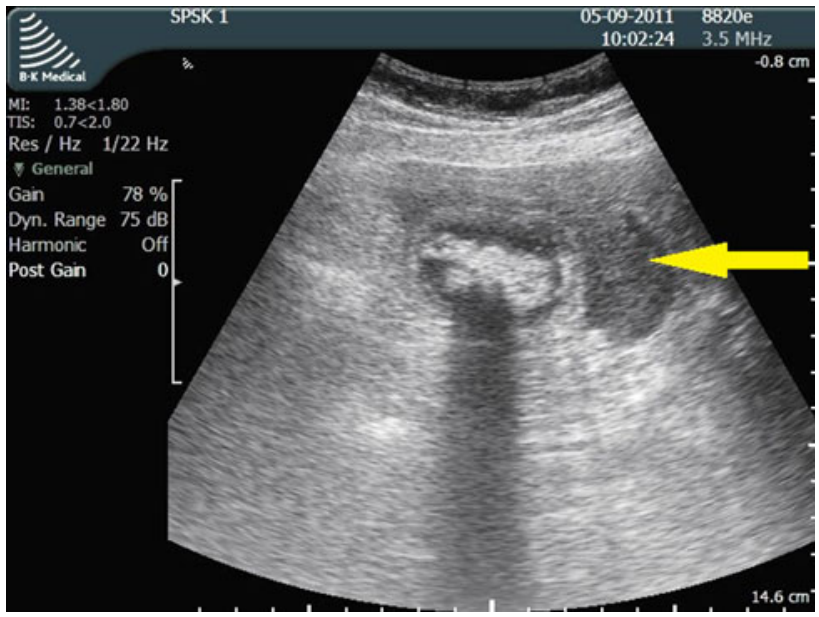

Fig. 5 Ultrasound findings in acute cholecystitis that could affect the outcome of surgery: a severe inflammation and thickening of the gallbladder wall; on the liver side a fluid collection (pericholecystic abscess) is visible

\section{References}

1. Sakuramoto S, Sato S, Okuri T, Sato K, Hiki Y, Kakita A (2000) Preoperative evaluation to predict technical difficulties of laparoscopic cholecystectomy on the basis of histological inflammation findings on resected gallbladder. Am J Surg 179:114-121

2. Assaff Y, Matter I, Sabo E, Mogilner J, Nash E, Abrahamson J, Eldar S (1998) Laparoscopic cholecystectomy for acute cholecystitis and the consequences of gallbladder perforation, bile spillage, and loss of stones. Eur J Surg 164:425-431

3. Cwik G, Wallner G, Ciechański A, Paździor M (2000) Ostre zapalenie pęcherzyka żółciowego-kwalifikacja do cholecystektomii laparoskopowej w ocenie USG. Pol Przeg Chir 72:351-362 
4. Eldar S, Sabo E, Nash E, Abrahamson J, Matter I (1998) Laparoscopic cholecystectomy for the various types of gallbladder inflammation: a prospective trial. Surg Laparosc Endosc 8:200-207

5. Fried G, Barkun J, Sigman H, Lawrence J, Clas D, Garzon J, Hinchey J, Meakins J (1994) Factors determining conversion to laparotomy in patients undergoing laparoscopic cholecystectomy. Am J Surg 167:35-41

6. Lal P, Agarwal PN, Malik VK, Chakravarti AL (2002) A difficult laparoscopic cholecystectomy that requires conversion to open procedure can be predicted by preoperative ultrasonography. JSLS 6:59-63

7. Kiviluoto T, Siren J, Luukkonen P, Kivilaakso E (1998) Randomized trial of laparoscopic versus open cholecystectomy for acute and gangrenous cholecystitis. Lancet 351:321-325

8. Reddick E, Olsen D, Spaw A (1991) Safe performance of difficult laparoscopic cholecystectomies. Am J Surg 161:377-381

9. Zucker K, Flowers J, Bailey R, Graham S, Buell J, Imbembo A (1993) Laparoscopic management of acute cholecystitis. Am J Surg 165:508-514

10. Michalowski K, Bornman P, Krige J, Gallagher P (1998) Laparoscopic subtotal cholecystectomy in patients with complicated acute cholecystitis or fibrosis. Br J Surg 85:904-906

11. Peters J, Krailadsiri W, Incarbone R, Bremner C, Froes E, Ireland A, Crookes P, Ortega A, Anthone G, Stain S (1994) Reasons for conversion from laparoscopic to open cholecystectomy in an urban teaching hospital. Am J Surg 168:555-559

12. Vauthey J, Lerut J, Martini M, Becker Ch, Gertsch P (1993) Indications and limitations of percutaneous cholecystostomy for acute cholecystitis. Surg Gynecol Obstet 176:49-54

13. Cox M, Wilson T, Luck A, Jeans P, Padbury R, Toouli J (1993) Laparoscopic cholecystectomy for acute inflammation of the gallbladder. Ann Surg 218:630-634

14. Rattner D, Ferguson C, Warshaw A (1993) Factors associated with successful laparoscopic cholecystectomy for acute cholecystitis. Ann Surg 217:233-236

15. Tayeb M, Raza SA, Khan MR, Azami R (2005) Conversion from laparoscopic to open cholecystectomy: multivariate analysis of preoperative risk factors. J Postgrad Med 51:17-20

16. Lujan J, Parilla P, Robles R, Martin P, Torralba J, Garcia J (1998) Laparoscopic cholecystectomy vs open cholecystectomy in treatment of acute cholecystitis. Arch Surg 133:173-175

17. Koperna T, Kisser M, Schulz F (1999) Laparoscopic versus open treatment of patients with acute cholecystitis. Hepatogastroenterology 46:753-757

18. van der Velden J, Berger M, Bonjer H, Brakel K, Lameris J (1998) Can sonographic signs predict conversion of laparoscopic to open cholecystectomy? Surg Endosc 12:1232-1235

19. Lipman JM, Claridge JA, Haridas M, Martin MD, Yao DC, Grimes KL, Malangoni MA (2007) Preoperative findings predict conversion from laparoscopic to open cholecystectomy. Surgery 142:556-565

20. Liu K, Richter H, Cho M, Jarad J, Nadimpalli V, Donahue P (1997) Carcinoma involving the gallbladder in elderly patients presenting with acute cholecystitis. Surgery 122:748-756

21. Sikora S, Kumar A, Saxena R, Kapoor V, Kaushik S (1995) Laparoscopic cholecystectomy-can conversion be predicted? World J Surg 19:858-860

22. Yamaguchi K, Chijiiwa K, Ichimiya H, Sada M, Kawakami K, Nishikata F (1996) Gallbladder carcinoma in the era of laparoscopic cholecystectomy. Arch Surg 131:981-985
23. van der Steeg HJJ, Alexander S, Houterman S, Slooter GD, Roumen RMH (2011) Risk factors for conversion during laparoscopic cholecystectomy-experiences from a general teaching hospital. Scand J Surg 100:169-173

24. Khan IA, El-Tinay OE (2004) Laparoscopic cholecystectomy for acute cholecystitis. Can preoperative factors predict conversion? Saudi Med J 25:299-302

25. Fraser SA, Sigman H (2009) Conversion in laparoscopic cholecystectomy after gastric resection: a 15-year review. Can J Surg 52:463-466

26. Dinkel HP, Kraus S, Heimbucher J, Moll R, Knüpffer J, Gassel HJ, Freys SM, Fuchs KH, Schindler G (2000) Sonography for selecting candidates for laparoscopic cholecystectomy: a prospective study. AJR Am J Roentgenol 174:1433-1439

27. Jatzko G, Lisborg P, Pertl A, Stettner H (1995) Multivariate comparison of complications after laparoscopic cholecystectomy and open cholecystectomy. Ann Surg 221:381

28. Kauvar D, Braswell A, Brown B, Harnisch M (2006) Influence of resident and attending surgeon seniority on operative performance in laparoscopic cholecystectomy. J Surg Res 132:159-163

29. Cho KS, Baek SY, Kang BCh, Choi HY, Han HS (2004) Evaluation of preoperative sonography in acute cholecystitis to predict technical difficulties during laparoscopic cholecystectomy. J Clin Ultrasound 32:115-122

30. Parmeggiani D, Cimmino G, Cerbone D, Avenia N, Ruggero R, Gubitosi A, Docimo G, Mordente S, Misso C, Parmeggiani U (2010) Biliary tract injuries during laparoscopic cholecystectomy: three case reports and literature review. G Chir 31:16-19

31. Genc V, Sulaimanov M, Cipe G, Basceken SI, Erverdi N, Gurel M, Aras N, Hazinedaroglu SM (2011) What necessitates the conversion to open cholecystectomy? A retrospective analysis of 5,164 consecutive laparoscopic operations. Clinics 66:417-420

32. Trondsen E, Edwin B, Reiertsen O, Foerden A, Fagertun H, Rosseland A (1998) Prediction of common bile duct stones prior to cholecystectomy. Arch Surg 133:162-166

33. Shapiro A, Costello C, Harkabus M, North J (1999) Predicting conversion of laparoscopic cholecystectomy for acute cholecystitis. JSLS 3:127-130

34. Ilie AC, Nica C, Szucsik IA, Motoc A, Sava A, Grosu S (2009) Preoperative ultrasonography as a mean of predicting the conversion of mini cholecystectomy into classic cholecystectomy. Rev Med Chir Soc Med Nat 113:1136-1140

35. Lim KR, Ibrahim S, Tan NC, Lim SH, Tay KH (2007) Risk factors for conversion to open surgery in patients with acute cholecystitis undergoing interval laparoscopic cholecystectomy. Ann Acad Med Singap 36:631-635

36. Golea A, Badea R, Şuteu T (2010) Role of ultrasonography for acute cholecystic conditions in the emergency room. Med Ultrasonogr 12:271-279

37. Summers SM, Scruggs W, Menchine MD, Lahham S, Anderson C, Amr O, Lotfipour S, Cusick SS, Fox JC (2010) A prospective evaluation of emergency department bedside ultrasonography for the detection of acute cholecystitis. Ann Emerg Med 56:114-122

38. Lee NW, Collins J, Britt R, Britt LD (2012) Evaluation of preoperative risk factors for converting laparoscopic to open cholecystectomy. Am Surg 78:831-833 